\title{
Non-Phosphopeptide Inhibitor for Lck SH2 Domain: Solid-Phase Synthesis and Structure Activity Relationship of Rosmarinic Acid Analogs
}

\author{
Sun Hee Kang, See-Hyoung Park, Hỵeung Soo Shim, and Keun-Hyeung Lee"

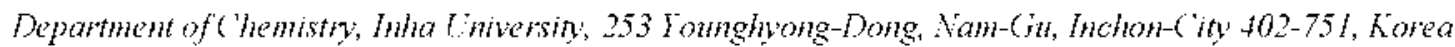 \\ †Signal Transthaction Laboratory, Mogam Biotechnology Research Institute, 34 I Poing-Ri, \\ Koosung-Wym, Fongin-City, Kyunggi-Do 419-910, Korea \\ Received Janamy, 20, 2003
}

Key Words : Lck SH2, Non-phosphopeptide, Rosmarinic acid. FI ISA. Inhibitor

SH2 domains play a critical role in organizing coherent signal transducing complexes that are essential for the appropriate cellular response to extracellular stimuli. ${ }^{3}$ Ligands that are able to disrupt these inappropriately hyperstimulated pathways. by blocking $\mathrm{SH} 2$ domain-dependent interactions, may ultimately be developed to therapeutic agents. ${ }^{2-4}$ For example. ligands directed against the $/ c k \mathrm{SH} 2$ domain could serve in various capacities. such as for the treatment of autoimmune disease and $\mathrm{T}$ cell-based leuckemias and lymphomas. Recent studies about peptide inhibitors for $\mathrm{SH} 2$ domain revealed that $\mathrm{SH} 2$ domains including $s^{\prime} c$ and $l c k$ exlubited a marked preference for the sequence -pYEElE-. and that short peptides bearing this sequence exhibited a reasonably high affinity for src family $\mathrm{SH} 2$ domains. ${ }^{3-5}$

Although moderately high-affinity phosphopeptide-based ligands for $\mathrm{SH} 2$ domains have been reported. their utility as therapeutic agents is obscure because of low resistance against phosplatase and protease and cell penetration ability. As an alternative way to develop non-phosphopeptide inhibitor for $\mathrm{SH} 2$ domains, natural chemical compounds were screened. Previously: we reported that (R) or (S) rosmarinic acid (RosA) had considerable inhibitory activities on $/ c k$ SH2-pYEEI interaction in Enzyme linked immunosorbent assay (ELISA). ${ }^{6}$ Furthermore, (R) RosA was reported to inhibit T-cell antigen receptor (TCR)-induced interleukin (IL)-2 expression and subsequent T-cell proliferation in vitro.

Considering the recent rational design of non-phosphopeptide inhibitors for $\mathrm{SH} 2$ domain, the size of the inlibitors was commonly simular to that of tripeptide or tetrapeptide because this size seemed to be optimum for the interactions of inhibitors with the surface of $\mathrm{SH} 2$ domains including $\mathrm{pY}$ pocket and for the cell penetration. Although RosA had an inhibition activity for T-cell proliferation in wirro cell assay, the binding affinity of the compound for $/ c k \mathrm{SH} 2$ domain was not potent. As RosA was smaller than tripeptide. it is possible to design RosA analogs with high binding affinity to $\mathrm{SH} 2$ domain by appending amino acids at the C-terminus of RosA.

In the present study: novel non-phosphopeptide inhibitors on the basis of the structure of RosA were synthesized by appending natural amino acids at the C-terminus of RosA in solid phase synthesis and their binding affinities to $/ c k \mathrm{SH} 2$ domain were investigated.

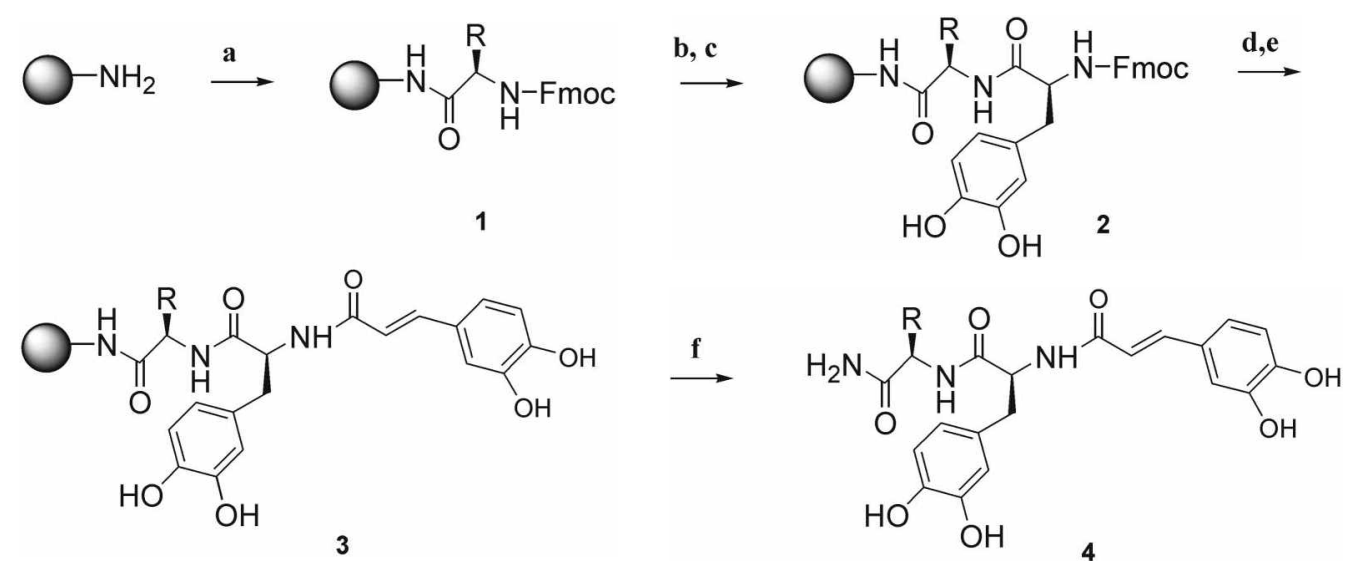

Scheme 1. (a) is equiv Fmoc- $\triangle \wedge-O H, D C C$, HOBt, DMF: (b) Piperidine, DMF: (c) i equiv Fmoc-DOPA, DCC: HOBt, DMF: (d)

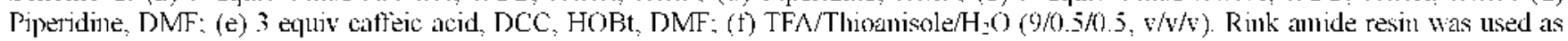
solial support. 


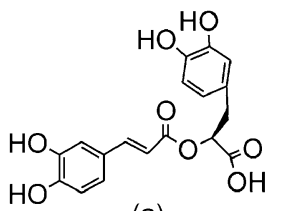

(a)<smiles>O=C(O)/C=C/c1ccc(O)c(O)c1</smiles>

(b)

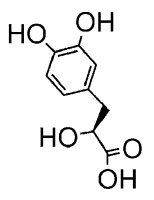

(c)
Figure 1. Structures of rosmarinic acid (a). cafleic acid (b). and 3.4-dihydroxylphenylacetic acid (c).

\section{Parallel Solid-phase Synthesis of Rosmarinic Acid Analogs}

To develop more potent SH2 inhibitor analogs, natural amino acid was appending at the C-terminus of $\operatorname{Ros} \Lambda$ in solid phase synthesis described in Seheme 1 . As Ros $\Lambda$, a natural plant metabolite, was naturally isolated, it is difficult to get Ros $\Lambda$ as g scale. In addition, the coupling efliciency of RosA to amino acids attached on the resin in solid phase was low |data not shown|. Ros $A$ was structurally divided into two compounds, caffeic acid and 3,4-dihydroxylphenylacetic acid as shown in Figure I. Jowever, 3,4-dihydroxylphenylacelic acid is not commercially available, whereas structurally similar compound, [.-3-(3,4-dihydroxylphenyl)alanine (1.-DOPA) is commercially available and can be more elficiently coupled with the acid compound.

Thus, using cafleic acid, [-DOPA, and natural amino acids as a monomer, we synthesized $\operatorname{Ros} \Lambda$ analogs containing Ros $A$ moicty and amino acid moiely in solid phase synthesis. shown in Scheme I. Fmoc protected natural amino acids except cysteme were coupled with amino group on Rink amide resin by using DCC/L IOBt coupling reagent. $\Lambda$ fter removal of the Fmoc-group of amino acid attached resin by treatment of $50 \%$ piperidine in DMF, Fmoc-DOPA ${ }^{8}$ was coupled with the amino acid on resin by using DCC/LIOBt coupling reagent. After deprotection of Fmoc group, cafleic acid was introduced to the resin by using the same coupling reagent. Each coupling reaction in solid phase was repeated

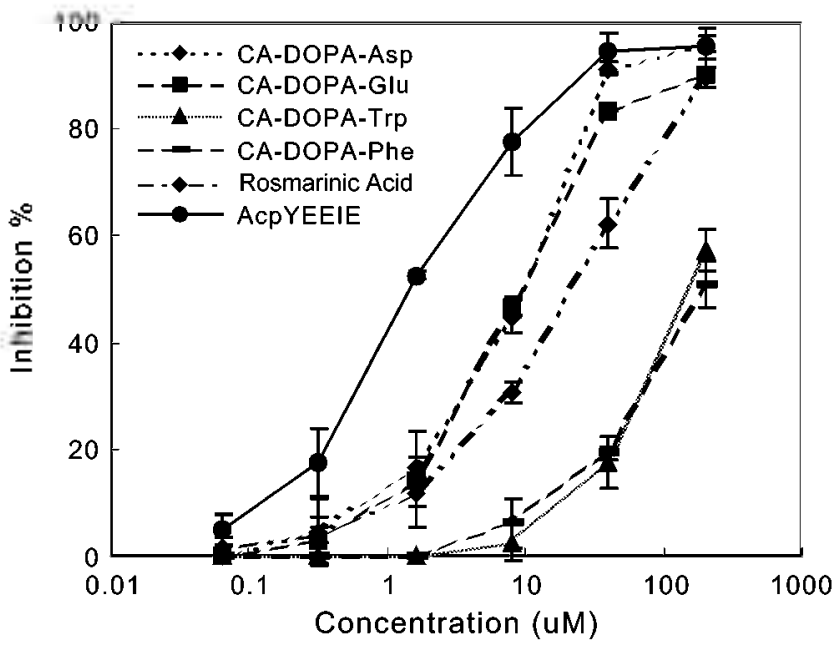

Figure 2, The inhibition activity of RosA analogs on lek SII2AcpYIIIII: interaclion by using IIIISA.

until no color change of the resin was monitored in ninhydrin 1est. "Clcavage and deprotection were achicved by treatment with a mixture of trilluoroacelic acid (TFA)/ $\mathrm{I}_{2} \mathrm{O}$ thioanisole $(9 / 0.5 / 0.5, \mathrm{v} / \mathrm{v} / \mathrm{v})$ at room lemperature for $8-9 \mathrm{~h}$. Each compound was purilicd by preparative reverse phase high performanee liquid chromalography. The yiclds of each product were over $70 \%$ and the products were oblained in high purily (generally $>95 \%$ by RP analyical IIPLC, $\left.\mathrm{UV}_{2 \mathrm{I}+\mathrm{mm}}\right)$. Electrospray mass spectrometry on a Platlorm II from VG (Manchester, UK) was used to characterize the mass and purity of the product generated from solid phase synthesis.

\section{Biological Results and Discussion}

The inhibition activity of Ros $\Lambda$ analogs on tck StI2$\Lambda$ cp YEElE- interaction was investigated by using the previously reported ELISA method. ${ }^{10} \Lambda$ s shown in Figure 2.

Table 1. The binding affinity of RosA analogs. Ros A. and Ac-pYEEIE for $/ c k \mathrm{SH} 2$ domain ${ }^{a}$

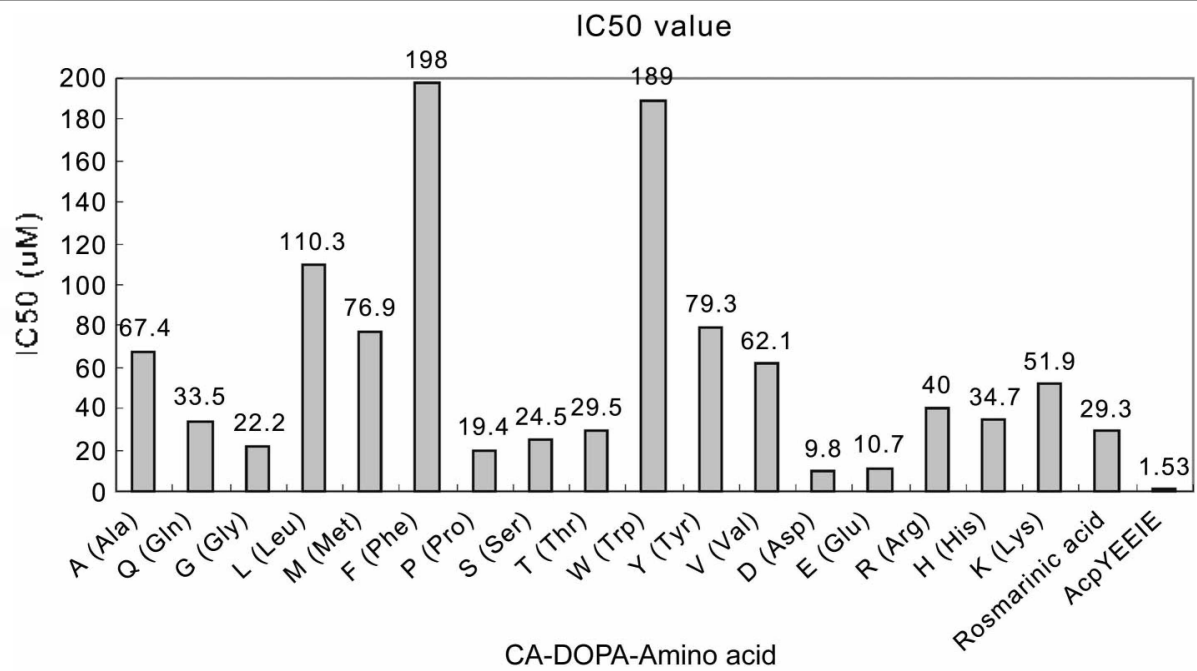

"Average $I C$ sil values were measured from three independent expetiments performed in duplicate. which provided a standard deviation below $20 \%$ 
synthesized rosmarinic analogs, RosA, and Ac-pYEEIEinlibited the binding of EPQPYEEIPIYL with /ck $\mathrm{SH} 2$ domain in a concentration-dependent manner. Table l summarized the results obtained in the ELISA assay. Appending natural amino acids at the C-teminus of RosA have a considerable effect on the binding affinity: The most potent Ros A analogs in this series had negatively charged amino acid at the C-terminus. Appending Asp and Glu amino acids at the $\mathrm{C}$-tenminus improved binding affinity three times on the basis of $\mathrm{IC}_{5 !}$ value. Positively charged amino acids were well distributed on the surface of $l c k \mathrm{SH} 2$ domain including $\mathrm{pY}, \mathrm{pY}-1$. and pY-2 binding sites. ${ }^{1]}$ Thus cliarge interactions between the compounds and $/ c k \mathrm{SH} 2$ domain must play a dominant role in the binding affinity. The result is consistent with the previous reported screening result for phosphopeptide inhibitors for s.c $\mathrm{SH} 2$ and $/ c k \mathrm{SH} 2$ domains by using combinatorial peptide libraries in which the phosphopeptide with more negatively charged amino acids exlubited more potent binding affinity to the proteins. ${ }^{5 / 15}$ Appending lỵdrophilic amuno acid (Ser. Thr, Gly, and Gln) retained or improved inlubition activity slightly, whereas the introduction of small aliphatic amino acid such as Ala. Val. Leu. and Met at the C-terminus resulted in the decrease of inhibition activity. Interestingly, the introduction of Pro at the C-terminus improved inluibition activity, which suggesting the possibility of developing novel RosA analog inhibitors for $\mathrm{SH} 2$ domain by introducing various secondary amines at the C-terminus of RosA. The introduction of aromatic amino acids (Trp and Phe) except Tyr resulted in a considerable loss of binding affinity to $/ \mathrm{ck} \mathrm{SH} 2$. However introduction of charged amino acids (Arg. Lys. and His) had a little effect on the binding affinity: which indicated that charged side chains of the amino acids were away from the surface of $/ c k \mathrm{SH} 2$.

Accordingly; overall result indicated that the increase of negative charge at the C-terminus of RosA had a positive effect on the binding affinity to $/ c k \mathrm{SH} 2$ domain while the increase of hydrophobicity by appending aromatic ring and aliphatic chain at the C-terminus induced a considerable negative effect on the binding affinity to the protein. Considering the binding affinity only. RosA-Glu and RosAAsp could be valuable lead compounds. However considering binding affinity as well as molecular weight and charge reduction for cell penetration. RosA-Pro could be a novel candidate to be developed for effective $\mathrm{SH} 2$ inhibitors.

We did not have direct information about RosA binding site for $k k \mathrm{SH} 2$ domain. however. the append of amino acids at the C-teminus of RosA provided important information for the binding mode of RosA with /ck $\mathrm{SH} 2$ domain and for the design of novel non-phosphopeptide $\mathrm{SH} 2$ inhibitors.

Acknowledgement. This work was supported by grant (No. R01-2001-00057-0) from the Basic Research Program of the Korea Science \& Engineering Foundation.

\section{References}

1. Cantley, I. C.: Nuger, K. R.: Carpenter, C.: Duckworth, B.: Graziani, A.: Kappeller, R.: Soltott'. S. C.//1991, 64, $2+1$.

2. Botlield. M. C.: Green. J. Lhm. Rep. Wed (hem. 1995. 30. 227.

3. (a) Garcia-Echeverria. C. C'urr. Hed Chem 2001. 13. 1589. (b) Broadbridge. R. J.: Sharma. R. P. ("uremt Drug Targets 2000. I. 365. (c) Bcaulicu. P. I..: Cameron, D. R.: Ferland, I. M.: Gauthicr, I.: Ghim, F.: Gillard, I. Gorys. V: Poirier, M.: Rancourt, I.: Wertic, D.: I linas-Brunet, M.: Betageri. R.: Cardozo. M.: Hickey. E. R.: Ingraliam. R.: Jakes. S.: Kabcenell. A.: Kirrane. T.: Lukas. S.: P'alel. U.: P'rond ool. J:: Sharma. R.: long. L.: Moss. N. J. led Chem 1999. 42. 1757. (d) Morelock. M. M.: Ingraham. R. H.; Betageri. R.; Jakes. S. J. Med. Chem. $1995,38.1309$

4. Vu. C. З. Cmm Hed Chem 2000. 10. 1081.

5. Songyang. Z.: Shoelson. S. E.: Chaudhuri. M.: Gish. G.: P'an son. l.: Haser. W. G.: King. F.: Roberts. T.: Palnofsky. S.: Lechleider. R. J.: Neel. B. G.: Birge. B.: Cantley. L. C. Cell 1993. 72. 767.

6. IJur. Г. M.: Choi, B.: Park. C.: I.ce. I.: Park. D.: Yun, Y.: I.e. K. II.: Oh. I. Г.: Ahn, C. S.: I.ce. II. S.: Ahn, I. S.: Jung. S. I. L.S. 6.140 .363 Oetober 31.2000 .

7. Won. J.: Hur. E. M.: Hur. Y: Park. S.: Kang. M.: Choi. Y.: Park. C.: Lee. K. H.: Yun. Y. Fur J. Inmmology 2003. 33.870.

8. Hu. B.: Messersmith. P?. B. Tetrohedron Lett. 2000. H. 5795 .

9. Kaiser, F.: Colescott, R. I..; Bossinger. C. D.: Cook, P. I. Alnat. Biochem. 1970. 34, 595

10. Gilmer, T.: Rodriguez. M.; Jordan, S.: Crosby R.: Alligood. K.: Green. K.: Kimery. M.: Wagner. C.: Kinder. D.: Charifson. I': Hassell. A. M.: Willard. D.: Luther. M.: Rusnak. D.: Sternbach. D. D.: Melhrotra. M.: P'eel. M.: Shampine. L.: Davis. R.: Robbins. I.: Patel. I. R.: Kasscl. D.: Burkhart. W: Mover. M.: Bradslaw; T.: Berman. J. J. Biot. Chem. 1994, 269. 31711.

11. T.ch, M. I.: Atwell. S. K.: Shoelson. S. F.: H Jarrison, S. C. Suture 1994. 368.764 